\title{
NOTES
}

\section{Stereoselective Bulk Polymerization of Racemic Lactide for Stereoblock Poly(racemic lactide) Using an Achiral Aluminum Complex}

\author{
Ryohei IsHII, Nobuyoshi NOMURA, ${ }^{\dagger}$ and Tadao KONDO \\ Laboratory of Polymer Chemistry, Graduate School of Bioagricultural Sciences, Nagoya University, Nagoya 464-8601, Japan
}

(Received December 15, 2003; Accepted January 15, 2004)

\begin{abstract}
KEY WORDS Stereoselective Polymerization / Bulk Polymerization / Isotactic Polylactide / Racemic Lactide / Achiral Catalyst /
\end{abstract}

Poly(L-lactide) (PLLA) is a renewable and environmentally benign polymer with biodegradable and biocompatible features and becomes one of the most promising and versatile materials. ${ }^{1}$ PLLA is commercially synthesized via the ring-opening polymerization of L-lactide with high enantiomeric purity, because the polymerization of lactide with low optical purity using conventional catalysts affords amorphous polylactide due to its stereoirregularity. The relatively rapid decomposition of polylactide is also known ${ }^{2}$ when heated above its $T_{\mathrm{m}},{ }^{3}$ so that polylactide with higher $T_{\mathrm{m}}$ is attractive in practical use. Recent highly stereoselective polymerization studies of racemic lactide (rac-LA) in solution ${ }^{4-6}$ allowed one to synthesize even a thermally more stable isotactic poly(rac-LA) $\left(T_{\mathrm{m}}\right.$ up to $192{ }^{\circ} \mathrm{C}$, Scheme 1) than homochiral PLLA ${ }^{7}$ owing to the stereocomplex formation between PLLA blocks and poly(D-lactide) (PDLA) blocks. From the standpoint of their industrial applications, the solvent-free polymer synthesis (bulk polymerization) has many advantages as compared with the solution one, i.e., environmental friendliness without solvents, low cost, and advantages of management and technical production. The industrial bulk process for the synthesis of PLLA adopts a high reaction temperature $\left(\sim 180^{\circ} \mathrm{C}\right)$ to keep the reaction mixture molten for direct extrusion from the reactor. ${ }^{8}$ In this process, the amount of the catalyst must be reduced to a minimum level as a consequence of minimizing the contaminates in the product, therefore, a high catalytic activity is one of the essential

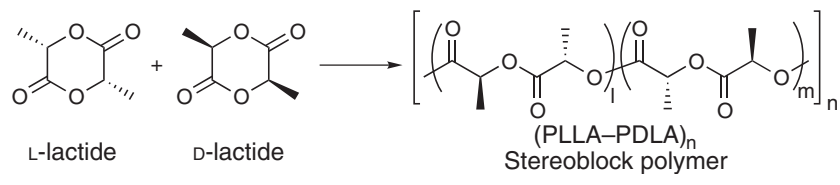

Scheme 1. Stereoselective isotactic polymerization of racemic lactide. components for the development of an industrial polymerization catalyst. Based on these considerations, the development of bulk polymerization catalysts combining high reactivity with high stereoselectivity, even at high temperatures, is a topic of practical precision synthesis. To the best of our knowledge, there is only one reaction reported by Feijen on the stereoselective bulk polymerization of rac-LA, ${ }^{\text {ba }}$ where the racemic chiral Jacobsen's salen ligand$\mathrm{AlO}$ Pr catalyst 1 was used, and crystalline poly(racLA) ( $T_{\mathrm{m}}$, not reported) was synthesized via the site control mechanism (Figure 1). The polymerization, however, is slow and needed $48 \mathrm{~h}$ at $130^{\circ} \mathrm{C}$ by the time the monomer conversion reached 95\% ([rac$\mathrm{LA}] /[\mathbf{1}]=200$ ). Hence, such a lower catalytic activity is far from practical applications. Here we report the highly reactive and stereoselective polymerization of rac-LA in bulk at $130-180^{\circ} \mathrm{C}$ using an achiral $\mathrm{Al}$ complex to produce the crystalline isotactic poly(rac$\mathrm{LA}$ ), in which the $T_{\mathrm{m}}$ values are comparable to that of homochiral PLLA. ${ }^{7}$

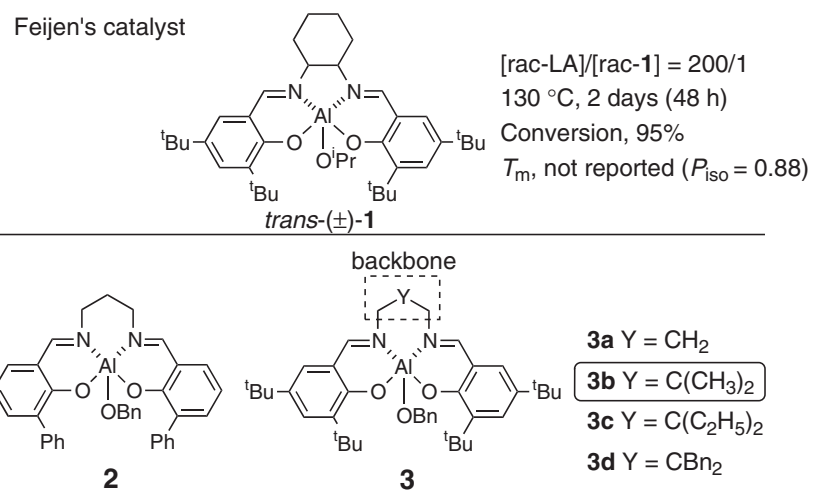

Figure 1. Stereoselective bulk polymerization catalysts of racemic lactide.

${ }^{\dagger}$ To whom correspondence should be addressed (Tel: +81-52-789-4139, E-mail: nnomura@agr.nagoya-u.ac.jp). 


\section{EXPERIMENTAL}

\section{Generals}

All manipulations were carried out using standard Schlenk-line techniques. ${ }^{1} \mathrm{H}$ NMR spectra were recorded on Varian Gemini-300 in $\mathrm{CDCl}_{3}$ for calculation of monomer conversion and on Bruker Avance 400 for characterization of complex $\mathbf{3 b}\left(\mathrm{C}_{6} \mathrm{D}_{6}\right)$ and polymer microstructure $\left(\mathrm{CDCl}_{3}\right)$. $\mathrm{N}_{2}$ was purified using a drycolumn $\left(T_{\mathrm{d}}\right.$ (dew point) $\leq-80^{\circ} \mathrm{C}$; NIKKA SEIKO Co., Ltd.) and a gas-clean column $\left(\mathrm{O}_{2} \leq\right.$ 0.002 ppm; NIKKA SEIKO Co., Ltd.). Differential Scanning Calorimetry (DSC) analyses were performed under $\mathrm{N}_{2}$ at a heating rate of $10^{\circ} \mathrm{C} / \mathrm{min}$ on a EXSTAR6000 by Seiko Instruments Inc. Molecular weights of the polymers were estimated by size-exclusion chromatography (SEC) using polystyrene standards $\left(\mathrm{CHCl}_{3}\right)$.

\section{Materials}

Toluene was distilled from $\mathrm{Na}$-benzophenone and $\mathrm{BnOH}$ and EtOAc were distilled from $\mathrm{CaH}_{2}$ under $\mathrm{N}_{2}$ prior to use. rac-LA was purchased from PURAC and was recrystallized in dry EtOAc three times. racLA was stored under $\mathrm{N}_{2}$ at $-40^{\circ} \mathrm{C}$. $\mathrm{Et}_{3} \mathrm{Al}$ in toluene solution $(0.93 \mathrm{M})$ was purchased from Kanto Chemical Co., Inc. and $0.10 \mathrm{M} \mathrm{Et}_{3} \mathrm{Al}$ solution was prepared by dilution of this solution $(1.0 \mathrm{~mL}, 0.93 \mathrm{mmol})$ with freshly distilled toluene $(8.3 \mathrm{~mL})$, and was stored under $\mathrm{N}_{2}$ at room temperature.

\section{Preparation of Catalysts (Table I)}

To a solution of each ligand $(0.050 \mathrm{mmol})$ in toluene $(0.50 \mathrm{~mL})$ was added $0.10 \mathrm{M} \mathrm{Et}_{3} \mathrm{Al}$ in toluene $(0.50 \mathrm{~mL}, 0.050 \mathrm{mmol})$ under $\mathrm{N}_{2}$ at room temperature. The clear solution was stirred at $70^{\circ} \mathrm{C}$ for $3 \mathrm{~h}$ (0.050 M catalyst).

\section{Polymerization (Table I)}

To rac-LA (720 mg, $5.0 \mathrm{mmol}$ ) and $0.10 \mathrm{M} \mathrm{BnOH}$ $(0.50 \mathrm{~mL}, 0.050 \mathrm{mmol})$ was added the solution (3a and $\mathbf{3 d}$ ) or suspension (3b and $\mathbf{3 c}$ ) of the $0.050 \mathrm{M}$ catalyst $(1.0 \mathrm{~mL}, 0.050 \mathrm{mmol})$ via a cannula at room temperature under $\mathrm{N}_{2}$. The catalyst flask was rinsed with toluene $(2.0 \mathrm{~mL}+1.5 \mathrm{~mL})$. The yellow mixture was heated at $70( \pm 1){ }^{\circ} \mathrm{C}$. The polymerization was traced with ${ }^{1} \mathrm{H}$ NMR and SEC analyses of small amounts ( $c a$. $5 \mathrm{mg}$ ) of the reaction mixture. After $6 \mathrm{~h}$, the reaction mixture was cooled at room temperature. Poly(racLA) was obtained by precipitation of the reaction mixture in cold $\mathrm{MeOH}$ (ca. $100 \mathrm{~mL})$.

\section{Synthesis of Complex $\mathbf{3 b}$}

To a yellow solution of the ligand $(494 \mathrm{mg}$,
$0.92 \mathrm{mmol})$ in toluene $(1.0 \mathrm{~mL})$ was added a solution of $\mathrm{Et}_{3} \mathrm{Al}$ in toluene $(0.93 \mathrm{M}, 1.0 \mathrm{~mL}, 0.93 \mathrm{mmol})$ at room temperature under $\mathrm{N}_{2}$. The yellow solution was stirred at room temperature until ethane was no longer formed. The reaction mixture was then heated at $70{ }^{\circ} \mathrm{C}$ for $3 \mathrm{~h}$ to give a yellow suspension. $\mathrm{BnOH}$ $(0.10 \mathrm{~mL}, 0.97 \mathrm{mmol})$ was added at room temperature and the mixture was stirred for $2 \mathrm{~h}$. Toluene $(1.5 \mathrm{~mL})$ was added, and the mixture was heated at $70^{\circ} \mathrm{C}$ that produced a light yellow solution. Complex $\mathbf{3 b}$ was precipitated after the solution remained at room temperature for 2 days $(272 \mathrm{mg}, 44 \%) .{ }^{1} \mathrm{HNMR}$ $\left(400 \mathrm{MHz}, \mathrm{C}_{6} \mathrm{D}_{6}\right): \delta 7.89(2 \mathrm{H}, \mathrm{d}, J=2.0 \mathrm{~Hz}), 7.63$ $(2 \mathrm{H}, \mathrm{s}), 7.36-7.16(5 \mathrm{H}, \mathrm{m}), 7.10 \quad(2 \mathrm{H}, \mathrm{d}, J=$ $2.0 \mathrm{~Hz}), 4.86(2 \mathrm{H}$, br s $), 3.35(2 \mathrm{H}, \mathrm{d}, J=12.2 \mathrm{~Hz})$, $2.77(2 \mathrm{H}, \mathrm{d}, J=12.1 \mathrm{~Hz}), 1.93(18 \mathrm{H}, \mathrm{s}), 1.49(18 \mathrm{H}$, s), $0.68(3 \mathrm{H}, \mathrm{s}), 0.51(3 \mathrm{H}, \mathrm{s}) .{ }^{13} \mathrm{C} \mathrm{NMR}(100 \mathrm{MHz}$, $\left.\mathrm{C}_{6} \mathrm{D}_{6}\right): \delta 24.99,25.54,30.18,31.66,34.15,35.43$, $36.06,65.90,67.86,119.05,126.96,127.41,128.53$, $130.56,138.09,141.18,164.10,170.31$.

\section{Polymerization Procedure (bulk)}

To rac-LA $(432 \mathrm{mg}, 3.0 \mathrm{mmol})$ was added the catalyst $\left(6.7 \mathrm{mg}, 0.010 \mathrm{mmol}\right.$ ) under $\mathrm{N}_{2}$. The mixture was heated at the prescribed temperature. After the appropriate time, the reaction mixture was cooled in a water bath (room temperature) and then dissolved with $\mathrm{CHCl}_{3}$. The $M_{\mathrm{n}}$ and $M_{\mathrm{w}} / M_{\mathrm{n}}$ of the crude polymer were directly measured by SEC. Poly(rac-LA) was obtained by precipitation of the reaction mixture in cold $\mathrm{MeOH}$.

\section{RESULTS AND DISCUSSION}

We previously reported the stereoselective ringopening polymerization of rac-LA in solution using the achiral ligand-Al complex $\mathbf{2}$ or $\mathbf{3 a}$ prepared in situ (Figure 1). ${ }^{5 \mathrm{e}}$ Due to the high reactivity of the Ph-substituted 2, we expected it could be a potential catalyst for the practical bulk polymerization. Although poly(rac-LA) was prepared within $10 \mathrm{~min}$ at $120^{\circ} \mathrm{C}$ in bulk polymerization using 2 ([rac-LA]/[2] $=300$, monomer conversion $\left.>95 \%, M_{\mathrm{w}} / M_{\mathrm{n}} 1.23\right)$, an unsatisfactory stereoselectivity was revealed by the low $T_{\mathrm{m}}$ value $\left(T_{\mathrm{m}} 132^{\circ} \mathrm{C}, \Delta H_{\text {fus }} 1.6 \mathrm{~J} / \mathrm{g}\right)$. Because of the low catalytic activity of tert-butyl-substituted 3a compared with 2, catalysts modified in the "backbone" were examined. Contrary to a racemic chiral complex such as 1, whose chiral sense comes from its backbone, the modification of the achiral backbone of $\mathbf{3 a}$ is easily accessible. Since the backbone connecting the two Schiff base moieties significantly influenced the catalytic activity, ${ }^{5 \mathrm{e}}$ we introduced several substituents to the backbone (3b-d). Interestingly, the introduction of two methyl-substituents increased the cata- 
lytic activity and maintained a high stereoselectivity (Table I, entry 2). On the other hand, the diethyl-substituted 3c had a low catalytic activity (entry 3), and the bulky two benzyl-substituents reduced the stereoselectivity as well as the catalytic activity (entry 4).

These results and our expectation that the lower catalytic activity of $\mathbf{3 b}$ than that of $\mathbf{2}$ could be overcome by high reaction temperature at sacrifice of some stereoselectivity prompted us to pursue bulk polymerization using $\mathbf{3 b}$. At first, complex $\mathbf{3 b}$ was isolated. The NMR spectra of the backbone in benzene- $d_{6}$ were characteristic as shown in Figure 2. In the ${ }^{1} \mathrm{H}$ NMR spectrum, a pair of doublet peaks appeared at 3.35 and $2.77 \mathrm{ppm}$ with a geminal coupling $(J \sim 12 \mathrm{~Hz}$, Figure 2a), which was substantiated by ${ }^{1} \mathrm{H}-{ }^{1} \mathrm{H}$ COSY, and two methylene carbons $\left(\mathrm{CH}_{2} \times 2\right)$ appeared at $67.86 \mathrm{ppm}$ as a single peak in the ${ }^{13} \mathrm{C}$ NMR (Figure

Table I. Substituent-effects of the backbone of $\mathbf{3}^{\mathrm{a}}$

\begin{tabular}{ccrrrrr}
\hline Entry & Catalyst $^{\mathrm{b}}$ & $\begin{array}{c}\text { Time } \\
(\mathrm{h})\end{array}$ & $\begin{array}{c}\text { Conv. }^{\mathrm{c}} \\
(\%)\end{array}$ & $M_{\mathrm{n}}{ }^{\mathrm{d}}$ & $M_{\mathrm{w}} / M_{\mathrm{n}}{ }^{\mathrm{d}}$ & $\begin{array}{c}T_{\mathrm{m}}{ }^{\mathrm{e}} \\
\left({ }^{\circ} \mathrm{C}\right)\end{array}$ \\
\hline $1^{\mathrm{f}}$ & $\mathbf{3 a}$ & 14 & 94 & 22400 & $1.0_{6}$ & 192 \\
2 & $3 \mathbf{b}$ & 6 & 90 & 19200 & $1.0_{6}$ & 192 \\
3 & $\mathbf{3 c}$ & 6 & 38 & 6900 & $1.0_{7}$ & 189 \\
4 & $\mathbf{3 d}$ & 6 & 57 & 14300 & $1.0_{6}$ & 175 \\
\hline
\end{tabular}

${ }^{a}$ All reactions were performed under $\mathrm{N}_{2}$ in toluene. $[\mathrm{rac}-\mathrm{LA}] /[3]=100 / 1 .{ }^{\mathrm{b}}$ Prepared in situ by mixing each ligand and $\mathrm{Et}_{3} \mathrm{Al}$ at $70^{\circ} \mathrm{C}$ for $3 \mathrm{~h}$ and then by the addition of $\mathrm{BnOH}$ (1 equiv. to $\mathrm{Et}_{3} \mathrm{Al}$ ) at room temperature. ${ }^{\mathrm{c}}$ Monomer conversion determined by ${ }^{1} \mathrm{HNMR}$. ${ }^{\mathrm{d}}$ The crude reaction mixtures without purification were measured by SEC (polystyrene standards, $\mathrm{CHCl}_{3}$ ). ${ }^{\mathrm{e}}$ Measured by DSC after purification in $\mathrm{MeOH} .{ }^{\mathrm{f}}$ Data from Ref 5e.

(a)

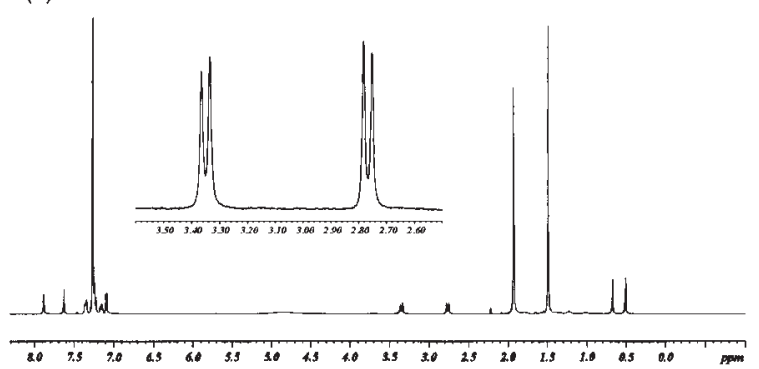

(b)

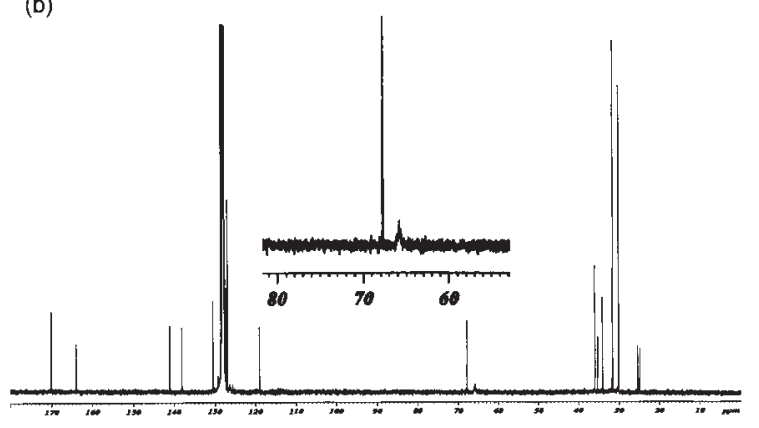

Figure 2. (a) ${ }^{1} \mathrm{H} N \mathrm{NR}(400 \mathrm{MHz})$; (b) ${ }^{13} \mathrm{CNMR}(100 \mathrm{MHz})$ spectra of $\mathbf{3 b}$ in $\mathrm{C}_{6} \mathrm{D}_{6}$.

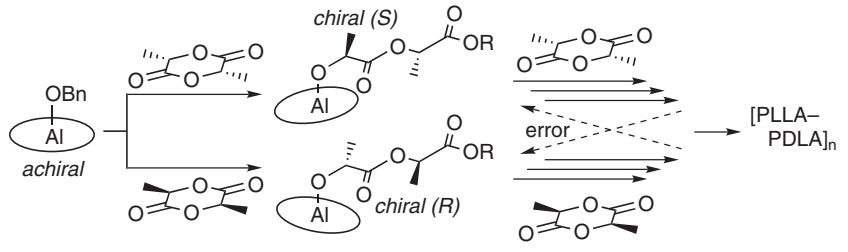

Scheme 2. Chain-end control mechanism using an achiral catalyst.

$2 b)$. These spectroscopic data showed that $\mathbf{3 b}$ is achiral in solution ${ }^{9}$ as well as its ligand, and that enantiomeric differentiation of rac-LA for propagation reactions should undergo the chain-end control by a chiral sense of the last-inserted monomer (Scheme 2), not the site control by the chirality derived from the rigid conformational enantiomers of 3b. To our surprise, both ${ }^{1} \mathrm{H}$ and ${ }^{13} \mathrm{C}$ NMR of benzylic $\mathrm{CH}_{2}$ peaks appeared as very broad peaks at $4.86 \mathrm{ppm}$ and $65.90 \mathrm{ppm}$, respectively. ${ }^{10}$

The results of the bulk polymerization of rac-LA using 3b $([\mathrm{rac}-\mathrm{LA}] /[\mathbf{3 b}]=300)$ are summarized in Table II. Achiral catalyst $\mathbf{3 b}$ polymerized rac-LA with moderate stereoselectivity even at $180^{\circ} \mathrm{C}$ (entries $1-$ $3)$. After $5 \mathrm{~min}$, the monomer conversion reached $61 \%$, and the obtained poly(rac-LA) had a narrow polydispersity $\left(M_{\mathrm{w}} / M_{\mathrm{n}} 1.1_{3}\right)$ (entry 1$)$. The longer reaction time gradually broadened the polydispersity with the monomer conversion increasing. The obtained poly(rac-LA)'s in entries 1-3, however, were all crystalline $\left(\Delta H_{\text {fus }} 14 \mathrm{~J} / \mathrm{g}\right)$, and their $T_{\mathrm{m}}$ values were close to that of PLLA. ${ }^{7}$ A microstructural analysis of these poly(rac-LA)'s by $100 \mathrm{MHz}{ }^{13} \mathrm{CNMR}$ also showed the consistent stereoselectivity ${ }^{11}\left(P_{\text {meso }}{ }^{12} 0.80, P_{\text {iso }}{ }^{5 d}\right.$ $0.89)$. Even at the high temperature, the comparable stereoselectivity to that of Feijen's (Figure 1) was efficiently achieved ( $20 \mathrm{~min} v s .48 \mathrm{~h}$ ). The results in entries 1-3 indicate that $M_{\mathrm{n}}$ and $M_{\mathrm{w}} / M_{\mathrm{n}}$ practically affect neither the stereoregularity nor the $T_{\mathrm{m}}$ values. At $150{ }^{\circ} \mathrm{C}$, the polymerization rate decreased as expected (entry 4), while the $T_{\mathrm{m}}$ value was slightly higher $\left(\Delta H_{\text {fus }} 26 \mathrm{~J} / \mathrm{g}, P_{\text {meso }} 0.82, P_{\text {iso }} 0.90\right)$. At $130^{\circ} \mathrm{C},{ }^{13}$

Table II. Bulk polymerization of rac-LA using $3 \mathbf{b}^{\mathrm{a}}$

\begin{tabular}{cccccccc}
\hline Entry & $\begin{array}{c}\text { Temp. } \\
\left({ }^{\circ} \mathrm{C}\right)\end{array}$ & $\begin{array}{c}\text { Time } \\
(\mathrm{min})\end{array}$ & $\begin{array}{c}\text { Conv }^{\mathrm{b}} \\
(\%)\end{array}$ & $M_{\mathrm{n}}{ }^{\mathrm{c}}$ & $M_{\mathrm{w}} / M_{\mathrm{n}}{ }^{\mathrm{c}}$ & $\begin{array}{c}\text { Yield }^{\mathrm{d}} \\
(\%)\end{array}$ & $\begin{array}{c}T_{\mathrm{m}}{ }^{\mathrm{e}} \\
\left({ }^{\circ} \mathrm{C}\right)\end{array}$ \\
\hline 1 & 180 & 5 & 61 & 34200 & $1.1_{3}$ & 52 & 155 \\
2 & 180 & 10 & 76 & 44000 & $1.2_{6}$ & 75 & 155 \\
3 & 180 & 20 & 90 & 46500 & $1.3_{3}$ & 82 & 155 \\
4 & 150 & 30 & 61 & 36000 & $1.1_{2}$ & 57 & 158 \\
5 & 130 & 30 & 25 & 14300 & $1.0_{5}$ & 20 & 169 \\
\hline
\end{tabular}

${ }^{\mathrm{a}}$ All reactions were performed under $\mathrm{N}_{2}$. [rac-LA]/ $[\mathbf{3 b}]=300 / 1 .{ }^{\mathrm{b}}$ Monomer conversion determined by ${ }^{1} \mathrm{H}$ NMR. ${ }^{\mathrm{c}}$ Measurement of crude reaction mixtures by SEC (polystyrene standards, $\mathrm{CHCl}_{3}$ ). ${ }^{\mathrm{d}}$ Precipitated in cold $\mathrm{MeOH}$. ${ }^{\mathrm{e}}$ Measured by DSC. 
the obtained poly(rac-LA) showed the higher $T_{\mathrm{m}}$ value (entry $5, \Delta H_{\text {fus }} 30 \mathrm{~J} / \mathrm{g}, P_{\text {meso }} 0.84, P_{\text {iso }} 0.91$ ) which is as high as that of the homochiral PLLA. ${ }^{7}$ We also confirmed that the catalyst prepared in situ was also applicable in bulk polymerization after simple evaporation of toluene from the catalyst solution, and isolation of the complex was not necessarily required for this bulk polymerization.

In conclusion, we confirmed that complex $\mathbf{3 b}$ is achiral in solution by NMR, and developed an efficient stereoselective bulk system for rac-LA polymerization to obtain crystalline stereoblock poly(rac-LA) even at industrially favored $180^{\circ} \mathrm{C}$ via chain-end control mechanism.

Acknowledgment. This work was partly supported by The Sumitomo Foundation. A fellowship to R.I. from the Japan Society for the Promotion of Science for Young Scientists is also acknowledged.

\section{REFERENCES AND NOTES}

1. a) E. Chiellini and R. Solaro, Adv. Mater., 8, 305 (1996). b) T. Hayashi, Prog. Polym. Sci., 19, 663 (1994).

2. O. Wachsen, K. H. Reichert, R. P. Krüger, H. Much, and G. Schultz, Polym. Degrad. Stab., 55, 225 (1997).

3. $T_{\mathrm{m}}$ : melting temperature.

4. Synthesis of gradient PDLA-PLLA: N. Spassky, M. Wisniewski, C. Pluta, and A. Le Borgne, Macromol. Chem. Phys., 197, 2627 (1996).

5. Synthesis of (PLLA-PDLA) $)_{n}$ : a) M. Wisniewski, A. Le Borgne, and N. Spassky, Macromol. Chem. Phys., 198, 1227 (1997).

b) C. P. Radano, G. L. Baker, and M. R. Smith III, J. Am. Chem. Soc., 122, 1552 (2000).

c) T. M. Ovitt and G. W. Coates, J. Polym. Sci., Part A: Polym. Chem., 38, 4684 (2000).

d) T. M. Ovitt and G. W. Coates, J. Am. Chem. Soc., 124, 1316 (2002).

e) N. Nomura, R. Ishii, M. Akakura, and K. Aoi, J. Am. Chem. Soc., 124, 5938 (2002).

6. Synthesis of (PLLA-PDLA) ${ }_{n}$ :
a) Z. Zhong, P. J. Dijkstra, and J. Feijen, Angew. Chem., Int. Ed., 41, 4510 (2002).
b) Z. Zhong, P. J. Dijkstra, and J. Feijen, J. Am. Chem. Soc., 125, 11291 (2003).

7. The $T_{\mathrm{m}}$ value of homochiral PLLA is $162^{\circ} \mathrm{C}$ : N. Yui, in "Polymeric Materials Encyclopedia," J. C. Salamone, Ed., CRC Press, Boca Raton, FL, 1996, Vol 10, p 7947. The
PLLA $\left(M_{\mathrm{n}}\right.$ 12400) that we synthesized from LLA (Aldrich) using $\mathrm{Al}\left(\mathrm{O}^{\mathrm{i}} \mathrm{Pr}\right)_{3}$ in toluene at $70^{\circ} \mathrm{C}$ indicated its $T_{\mathrm{m}}$ at $164^{\circ} \mathrm{C}$.

8. H. R. Kricheldorf, Chemosphere, 43, 49 (2001).

9. The structure of $\mathbf{3 b}$ is expected to be square-pyramidal or trigonal-bipyramidal with some distortion as those of the related complexes (Ref 5a-d), and the most stable conformation of the simplistic complex of 3a by DFT(B3LYP/6$31 \mathrm{G}^{*}$ ) calculations (Ref 5e) also supported it. The structure of the complex $\mathbf{3 b}$ can not be $C_{2}$-symmetrical in solution, because the two methyl-groups of the backbone are not equivalent in ${ }^{1} \mathrm{H}$ and ${ }^{13} \mathrm{C} \mathrm{NMR}$ (see Experimental). If the conformation of $\mathbf{3 b}$ is rigid, four peaks for two methyleneprotons $\left(\mathrm{CH}_{2} \times 2\right)$ of the backbone should appear in ${ }^{1} \mathrm{HNMR}$, and two peaks for two methylene-carbons $\left(\mathrm{CH}_{2}\right.$ $\times 2$ ) should appear in ${ }^{13} \mathrm{CNMR}$. As shown in Figure 2, two methylenes are unambiguously identical in ${ }^{1} \mathrm{H}$ and ${ }^{13} \mathrm{CNMR}$ at $27{ }^{\circ} \mathrm{C}$, and they indicate that the conformation of $\mathbf{3 b}$ is flexible.

10. We also isolated the isopropoxide complex using 2-propanol instead of benzyl alcohol. In the ${ }^{1} \mathrm{H}$ NMR spectrum, both the methine and methyl protons of isopropoxide also appeared as broad peaks at 4.33 and $1.31 \mathrm{ppm}$, respectively.

11. In this paper, the stereoselectivity are indicated in two forms, $P_{\text {meso }}$ and $P_{\text {iso. }}$. Both of them are the probability of the same chiral sense linkage (meso/iso) on the basis of the stereoselective mechanism on the catalyst. Even in the same polymer, $P_{\text {meso }}$ and $P_{\text {iso }}$ give different numbers as shown. $P_{\text {meso }}$ should be used for evaluation in the chainend control mechanism (our system) to afford the stereoblock polymer (PLLA-PDLA) $)_{n} . P_{\text {iso }}$ is on the basis of the site control mechanism, in which each polymer molecule should be optically active either PLLA or PDLA. As Coates et al. demonstrated, ${ }^{5 \mathrm{c}, \mathrm{d}}$ the isotactic poly(rac-LA)'s via the site control mechanism are not the mixture of PLLA and PDLA but stereoblock (PLLA-PDLA) $n$ 's when the polymer exchanges occur after insertion of the mismatched monomer on the catalyst. As a matter of fact, the polymer exchanges also occurred in Feijen's system. ${ }^{6 \mathrm{~b}}$ We dared to calculate two forms $P_{\text {meso }}$ and $P_{\text {iso }}$ to compare our system (chainend control) with Feijen's (site control in the presence of polymer exchanges) because both cases afford the same (PLLA-PDLA) $)_{n}$. An unambiguous simple evaluation of isotacticity of the polymer molecules without mechanistic considerations (and assumptions) could be done by measurement of $T_{\mathrm{m}}$.

12. J. E. Kasperczyk, Macromolecules, 28, 3937 (1995): $P_{\text {meso }}$ is the probability of meso linkages in the chain-end control mechanism.

13. The monomer conversion reached $80 \%$ after $2 \mathrm{~h}$. 